УДК 378.6.016:81

DOI: $10.18384 / 2310-712 X-2018-6-91-100$

\title{
ОСОБЕННОСТИ ПЕРЕВОДА НАУЧНО-ПУБЛИЦИСТИЧЕСКИХ ТЕКСТОВ
}

\section{Мохова ОЛ.', Назарова Н.Б.', , Серебровская Т.Б. ${ }^{1}$}

${ }^{1}$ Московский сринансово-промышленный университет «Синергия» 129090, г Москва, ул. Мещанская, д. 9/14, стр. 1, Российская Федерация

2 Российский университет транспорта (МИИТ) 127994, г. Москва, ул. Образцова, д. 9, стр. 9, Российская Федерация

Аннотация. Статья посвящена проблеме перевода научно-публицистических текстов. В ней рассматриваются основные подходы к переводу лексических стилистических приёмов, встречающихся в специализированной литературе, и умение их грамотно интерпретировать с учётом лингвистических и структурных особенностей исходного текста. Используется сопоставительный анализ перевода с английского языка на русский. На основе проведённого анализа особенностей научно-публицистических текстов и их межъязыковой трансляции авторы приходят к выводу, что понимание переводчиком лексических, грамматических и стилистических приёмов во многом способствует правильному оформлению высказываний в языке перевода, посредством которых интенция автора и передаётся потенциальному получателю - носителю другого языка. Теоретическая значимость работы состоит в комплексном характере анализа особенностей научно-публицистических текстов и их межъязыковой трансляции (лексический, грамматический, синтаксический уровни) и пополнении системы знаний об эффективных способах межъязыковой коммуникации через специализированную литературу. Практическая значимость - в возможности использования наблюдений авторов статьи при подготовке переводчиков и в курсах повышения профессиональной компетенции.

Ключевые слова: научно-публицистический текст, стилистические приёмы перевода, лексические приёмы перевода.

\section{FEATURES OF THE TRANSLATION OF SCIENTIFIC TEXTS AT THE STYLISTIC LEVEL}

\section{O. Mokhova ${ }^{1}$, N. Nazarova ${ }^{1,2}$, T. Serebrovskaya ${ }^{1}$}

${ }^{1}$ Moscow University for Industry and Finance "Synergy"

9/14 build. 1 ulitsa Meshchanskaya, Moscow 129090, Russian Federation

${ }^{2}$ Russian University of Transport (MIIT)

9 build. 9 ulitsa Obraztsova, Moscow 127994, Russian Federation

Abstract. The article is devoted to the problem of translation of scientific texts. It examines the main approaches to the translation of lexical stylistic devices found in specialized literature, and the ability to interpret them correctly, taking into account the linguistic and structural features of the source text. The author comes to the conclusion that the interpreter's understanding of

(ㄷ СС ВY Мохова О.Л., Назарова Н.Б., Серебровская Т.Б., 2018. 
lexical, grammatical and stylistic devices greatly facilitate the correct formulation of statements in the target language, through which the author's intention is transmitted to the potential recipient - speaker of another language.

Key words: scientific and journalistic text, stylistic methods of translation, lexical methods of translation.

Научная публицистика призвана расширить аудиторию читателей. Научно-публицистическая статья, как правило, носит полемический характер и характеризуется тем, что ясность, лаконичность и доходчивость изложения направлены на привлечение особого внимания читателя. Автор научно-публицистической статьи может вводить в текст дополнительную информацию, демонстрируя тем самым свою начитанность и эрудицию. В такой статье автор имеет возможность представить интуитивные знания, предположения, сомнения, а также дать субъективную критическую оценку научному творчеству других членов научного сообщества и пр. В тексте могут присутствовать абстрактные слова и выражения, а также вводные слова и фразы, при исключении которых не произойдёт искажения смысла [5].

Научно-публицистический текст на лексико-семантическом уровне имеет ярко выраженные характерные особенности, к каковым можно отнести: широкое использование терминов, абстрактной лексики, интертекстуальность, особые словообразовательные средства, особую фразеологию, наличие клишированных конструкций. Все эти особенности связаны с функциональными задачами научного дискурca [14].

Английскому языку свойствен нейтральный стиль изложения, поэтому книжная лексика употребляется не так часто, как в русском языке, вместо это- го активно используются нейтральные слова, которые дополняются разговорными и экспрессивно окрашенными. В настоящее время в российскую публицистику активно проникают разговорные выражения и конструкции и происходит некоторое сближение с английским языком. Тем не менее стилистические средства любого языка были и продолжают оставаться лингвоспецифичными, так как языки отличаются жанрово-стилистическим своеобразием, что вызывает определённые трудности при переводе, для преодоления которых нужна осмысленная работа по сопоставлению особенностей двух языков. Таким образом, в статье рассматриваются вопросы, связанные с передачей стилистических трудностей при переводе газетно-публицистических текстов общеэкономического содержания с русского языка на английский [8].

Как показывает практика, авторы многих научно-публицистических текстов часто используют различного рода стилистические приёмы, такие как метафора, сравнение, повтор, аллюзия, ирония, олицетворение и мн. др. Очевидно, это связано с их желанием сделать текст не только информативным, но и, придав ему некоторую экспрессивность, вызвать интерес читающего к его содержанию, а также сделать процесс восприятия материала более доступным к пониманию. Создавая текст, используя в каждом конкретном коммуникативном речевом 
произведении определённый набор языковых средств и структур, автор рассчитывает на то, что адресат извлечёт из данного текста информацию, т. е. сформирует его определённую ментальную репрезентацию [6].

Задача переводчика в данном случае заключается в том, чтобы, по возможности, сохранить эмоциональный фон повествования, как можно более точно воспроизведя в переведённом варианте те выразительные языковые средства, которые и способствуют усилению коммуникативного эффекта исходного текста. При этом важно, чтобы перевод слова, фразы или предложения соответствовал той смысловой нагрузке, которую они несут на себе в оригинале. Чтобы добиться такого результата, переводчик должен иметь навыки, позволяющие ему не только быстро распознать тот или иной стилистический приём, используемый в исходном тексте, но и адекватно передать его в языке перевода [12, с. 29].

Показательным в этом отношении является пример перевода слова buyology, которое является ключевым в книге "Buy-Ology: How Everything We Believe about Why We Buy is Wrong”, написанной известным специалистом в области маркетинга Мартином Линдстромом.

Уже с самого начала игра слов, в основе которой лежит омонимия buyology и biology «биология» - создаёт юмористический эффект, хотя представленная в книге информация носит отнюдь не развлекательный характер. Наоборот, основываясь на результатах серьёзного исследования в области нейромаркетинга, автор достаточно глубоко анализирует факты, влияющие на принятие потенциальными по- купателями решения о приобретении того или иного товара.

And they will prove even more powerful in driving our loyalty, our minds, our wallets, and our Buyology than even the marketers themselves could have anticipat$e d$ - «они влияют на лояльность, сознание, кошельки и на науку о покупках в гораздо большей степени, чем можно было предположить».

Как кажется, переводчик в полной мере реализовал коммуникативную цель данного высказывания, скалькировав образующие его лексемы - buy покупать $+o+-\log y$ - логия (компонент сложных слов, обозначающий отрасль знания, науки), хотя в русском варианте от игры слов пришлось отказаться.

Также нужно отметить, что для любой отрасли, в том числе и экономики, характерно использование как индивидуальных, чисто авторских стилистически окрашенных лексических единиц, которые проиллюстрировал предыдущий пример, так и устоявшихся, которые давно и прочно закрепились в терминологическом корпусе данной сферы.

Более того, со временем у профессионального переводчика формируется когнитивная потребность к более глубокому ознакомлению с этимологической характеристикой подобной лексики. По мнению Н.Н. Гавриленко, «когнитивный аспект целей обучения при подготовке переводчика текстов по специальности соотносится с формированием и развитием его профессиональной компетентности» [3, c. 207].

Следует рассмотреть эту идею на примере перевода выражения "over the counter”, которое появилось в 1870-х гг. в США и изначально использовалось в 
своём прямом значении, а именно для описания практики покупки акций непосредственно у банковских стоек. И лишь гораздо позже это словосочетание приобрело статус экономического термина, в основе которого лежит метонимия.

After the IPO, the stock may trade on a stock exchange or over the counter - «после первичного публичного размещения акций они могут торговаться на фондовой бирже или на внебиржевом рынке».

Следующий пример также подчёркивает когнитивный аспект процесса перевода литературы по специальности, и в частности тогда, когда переводчику приходится иметь дело с трактовкой стилистических приёмов, содержащихся в тексте оригинала.

Conversely, if you're nearing retirement, a greater portion of your nest egg might be devoted to investments focused on income and preservation of your capital - «и наоборот, чем ближе ваш пенсионный возраст, тем большая доля ваших сбережений должна пойти на инвестирование, которое гарантирует вам прибыль и сохранение вашего капитала».

Термин “nest egg”, который, как и в предыдущем случае, представляет собой метонимию, используется в значении «сбережения» с конца XVII в. Считается, что своим появлением он обязан птицеводам, которые подкладывали в гнёзда яйца в качестве приманки для привлечения туда наседок, что, по их мнению, стимулировало куриц-несушек к откладыванию большего количества яиц, в результате чего доход этих птицеводов значительно увеличивался[12, с. 31, 32].

Выражение "nest egg" приобрело некоторую стилистическую коннотацию именно по аналогии с этой ситуацией и теперь в экономической литературе употребляется в следующем значении: деньги, откладываемые для получения дохода в пенсионный период.

Теперь, когда очерчен общий круг вопросов, которые неизбежно возникают в процессе порождения текста на языке перевода в случае необходимости воспроизведения в нём стилистических приёмов, присутствующих в оригинале, целесообразно рассмотреть основные подходы к переводу указанной категории лексических единиц. Как показывает практика, чаще всего в таких случаях используется либо семантический перевод, либо различного рода контекстуальные замены и трансформации [13, с. 73].

1. Семантический перевод стилистически окрашенных лексических единиц возможен тогда, когда степень их эквивалентности в обоих языках совпадает практически полностью. Например, в следующем предложении перевод иронического контекста, основанного на контрасте идей, который вводится союзом “but”, не требует никаких трансформаций или замен, но при этом абсолютно точно сохранены все ключевые элементы иронии.

Those against too much reliance on advertising are fond of quoting John Wanamaker of department store fame: "I know that half the money I spend on advertising is wasted; but I can never find out which half" - «А тем, кто считает, что слишком полагаться на рекламу не стоит, очень нравится известное высказывание Джона Уонамейкера: “Я знаю, что половина денег, которые я трачу на рекламу, выбрасывается на ветер, но никак не могу понять, какая именно половина"». 
Практически дословный перевод следующего предложения также характеризуется сохранением его семантической структуры в русском языке, за исключением лишь тех моментов, где переводчику с учётом контекста пришлось использовать ещё и приём добавления для конкретизации существительных communications и launch.

Reducing communications after the launch is like buying a treadmill, using it fervently during the first month and then using it as a clothes hanger - you don't get the results you were looking for - «сокращение масштабов информационного взаимодействия после запуска программы - это то же самое, как если бы вы купили беговую дорожку и активно использовали её только в первый месяц, а затем она стала для вас чем-то вроде вешалки для одежды - иными словами, вы не получили того результата, о котором мечтали».

Примечательным в этом отношении является следующий пример, который прекрасно иллюстрирует ситуацию, когда для перевода английского эмоционально окрашенного выражения вполне уместно употребить его русский аналог, однако дословный перевод стилистического приёма всё же более предпочтителен с точки зрения ассоциаций со специфическими национальными реалиями.

При работе с реалиями переводчика поджидают две основные трудности: отсутствие в переводящем языке, языке перевода (ПЯ), точного однословного соответствия переводимой реалии из-за того, что в культуре и быте носителей языка перевода нет обозначаемого данной реалией объекта, т. е. самого референта, и необходимость не только передать предметное значение реалии, но и сохранить её национальный и исторический колорит [1].

Так, английское выражение "to ask the fox to guard the henhouse" по смыслу и стилистической окраске полностью совпадает с русским идиоматическим выражением «пустить козла в огород», которое имеет ироническое значение, а именно 'позволять кому-либо действовать там, где он может быть особенно вреден; допускать кого-либо к тому, чем он может воспользоваться в корыстных целях'.

Однако, учитывая тот факт, что образ козла или козы, ассоциирующийся исключительно с никчёмностью и прочими отрицательными характеристиками персонажа (например, «как от козла молока», «лупить кого-то как сидорову козу», «на козе не подъедешь»), широко употребляется только в русских анимализмах, контекстуальная замена при переводе указанного выше английского выражения была бы неуместна.

Более того, поскольку исходный текст содержит информацию сугубо профессионального характера, написан формальным языком и относится к научно-публицистическому стилю, можно сделать вывод, что русский фразеологизм в переводе может показаться грубоватым, в то время как дословное сравнение полностью соответствует нормам речевого поведения, принятым в англоговорящих странах $[9$, c. 43,44$]$.

Even inside the AFL-CIO, a number of unions don't think it's possible to make the WTO enforce workers' rights. "It's like asking the fox to guard the henhouse", says Brian Williams - «Даже в самом Конгрессе ряд профсоюзов считают, что невозможно заставить ВТО принять 
меры по обеспечению соблюдения прав рабочих. "Это все равно, что просить лису охранять курятник”, - заявляет Брайан Уильямс».

В рамках рассматриваемой темы также следует отметить и те случаи, когда перевод лексических стилистических приёмов может быть исключительно дословным в силу того, что составляющие их элементы представлены именами собственными или словами и выражениями, содержащими намёк на какой-либо широко известный исторический, культурный, политический и прочий факт, который не нуждается в дополнительном комментарии.

Так, чтобы подчеркнуть некоторые отрицательные черты характера человека, в частности те, которые непосредственно относятся к лидерским качествам, автор нижеследующего высказывания прибегает к такому приёму, как антономазия, употребив во множественном числе имена собственные Attila и Machiavelli, в результате чего они стали восприниматься как имена нарицательные.

That there are modern-day Attilas and Machiavellis is obvious, and the same uncritical admiration is in evidence - "Coвременные Аттилы и Макиавелли существуют - это совершенно очевидно; также налицо и тот факт, что ими слепо восхищаются».

Оформляя свою мысль именно таким образом, автор основывался на идее, что то, что оба эти исторических персонажа олицетворяют собой абсолютно бескомпромиссный, часто граничащий с жестокостью подход к управлению государством, всем известный факт [12, с. 35].

2. Различного рода контекстуальные замены применяются тогда, когда дословный перевод невозможен в силу того, что в русском языке получившаяся фраза будет звучать абсолютно неидиоматично или того хуже, представлять собой просто набор слов [11, c. 83,84$]$.

Хорошо известно, что чрезмерная дословность приводит к появлению в тексте перевода несвойственных данному языку, неуклюжих словосочетаний, которые затрудняют восприятие перевода, искажают то общее воздействие подлинника, которое перевод в первую очередь обязан передать [2].

Приведённый ниже пример показывает, что даже при наличии в русском языке эквивалента для того или иного английского стилистически маркированного выражения часто приходится прибегать к заменам, используя лексические единицы языка перевода, значение которых совершенно не совпадает со словарным значением элементов исходного текста. Так, хотя между английским сравнением "to drop like a stone” и русским выражением «падать камнем вниз» наблюдается полное семантическое сходство, тем не менее последнее подходит не для каждого контекста, особенно если речь идёт о ситуациях, характеризующихся узкоспециальной направленностью.

But what if you've invested $\$ 10,000$ in the stock market and the price of the stock drops like a stone one day - «Но что, если вы вложили в фондовый рынок 10000 долл. и в один прекрасный день цена на акции резко обрушивается».

Несмотря на то, что вариант перевода «цена на акции словно падает камнем вниз» вполне понятен, он нарушает как лексические нормы русского языка, поскольку падать камнем может только физический объект, так 
в некоторой степени и стилистические нормы, поскольку указанное выражение характерно для художественных текстов, а не для отраслевой литературы. По этой причине переводчик, основываясь на смежности понятий, вполне уместно использовал приём смыслового развития, прибегнув к метонимической замене исходного выражения [7, с. 52].

Безусловно, предложенный вариант перевода не является стилистическим приёмом в русском языке, но и полностью нейтральным его назвать нельзя, поскольку некоторую динамику ему добавляет наречие «резко».

3. Трансформации, включающие в себя замену частей речи, числа существительного, грамматической структуры предложения и т. д., также являются важной характеристикой перевода лексических стилистических приёмов. Однако при этом нужно помнить, что любое преобразование исходного высказывания в языке перевода должно быть оправдано [10, с. 63, 64].

Так, в следующем примере перевод гиперболы “in a super rush” теми же частями речи, что и в оригинале, был бы некорректным, поскольку такая компоновка слов не согласуется с точки зрения лексических связей с остальными членами предложения. По этой причине представляется более правильным прибегнуть к замене частей речи и перевести это словосочетание придаточным определительным предложением «которые слишком торопятся».

Scrutinize unusually large orders and those customers in a super rush - "Тщательно проверяйте очень крупные заказы и тех клиентов, которые слишком торопятся».
Замена частей речи может быть необходима и по причине отсутствия в языке перевода грамматических эквивалентов для соответствующих категорий исходного языка, что можно проследить на примере герундия, который можно перевести на русский язык существительным, инфинитивом, деепричастием и даже придаточным предложением [4, с. 44].

В то же время следует учитывать и тот факт, что в разных традициях интернационализмы могут получать неоднозначное осмысление. Расхождения в толковании понятий, выражаемых с помощью интернациональных терминов, вытекают из особенностей профессиональной языковой картины мира и обусловливают необходимость уточнения специфики значения того или иного термина в составе данной терминологии [15].

Таким образом, следует сделать вывод, что понимание переводчиком лексических, грамматических и стилистических приёмов, встречающихся в специализированной литературе, и умение их грамотно интерпретировать с учётом лингвистических и структурных особенностей исходного текста во многом способствуют правильному оформлению высказываний в языке перевода, посредством которых интенция автора и передаётся потенциальному получателю - носителю другого языка. В определённой степени эти навыки также расширяют кругозор самого переводчика, что, несомненно, положительно влияет на формирование у него как общекультурной, так и профессиональной компетенций.

Статья поступила в редакцию 01.03.2018 


\section{ЛИТЕРАТУРА}

1. Артемьева Ю.В., Явари Ю.В. Перевод реалий в произведениях кинематографа // Вестник Московского государственного областного университета. Серия: Лингвистика. 2018. № 1. С. 101-109.

2. Беляева И.Ф., Хухуни Г.Т. «Переводческий буквализм»: страницы истории // Вестник Московского государственного областного университета. Серия: Лингвистика. 2016. № 1. С. $108-117$.

3. Гавриленко Н.Н. Профессионально-ориентированный перевод: реальность и перспективы. М.: Российский университет дружбы народов, 2016. 270 с.

4. Добрянская О.B. Money, banking, accounting. СПб.: Санкт Петербургский государственный университет экономики и финансов, 2010. 100 с.

5. Жирова И.Г. К вопросу о совмещении элементов научной, научно-публицистической и научно-популярной речи в стилистике и семантике научной статьи // Вестник Московского государственного областного университета. Серия: Лингвистика. 2016. № 2. C. 41-46.

6. Кардович И.К. О когнитивном анализе текста // Вестник Московского института лингвистики. 2011. № 2. С. 30-35.

7. Коваленко Г.Ф. Культура речевого общения и перевод (английский язык). Хабаровск: Издательство Тихоокеанского государственного университета, 2013. 75 с.

8. Коровкина М.Е. Способы преодоления несовпадений в стилистических приемах русского и английского языков при переводе // Вестник Московского государственного лингвистического университета. Серия: Гуманитарные науки. 2016. Вып. 11 (750). C. 13-24.

9. Кузнецова А.В. Письменный перевод. Английский язык. Магнитогорск: Издательство Магнитогорского государственного университета, 2011. 300 с.

10. Купцова А.К. Устный перевод (Экономика и бизнес). Английский язык. М.: Институт МИРБИС , 2013. 182 с.

11. Маньковская 3.В. Английский язык в ситуациях повседневного делового общения. М.: ИНФРА-М, 2012. 223 c.

12. Миголатьева И.В. Устный перевод общественно-политических текстов. Английский язык. М.: Российский университет дружбы народов, 2014. 47 с.

13. Пересунько Е.А. Деловой английский. М.: Издательство Московского государственного университета леса, 2012. 100 с.

14. Сказко А.С., Агирбов С.Р. Лексико-семантические особенности научно-публицистического философского текста на английском языке // Наука и современность. 2011. № 13-3. С. 45-48.

15. Чернышова Л.А Интернациональные термины как компонент профессиональной языковой картины МИРА // Вестник Московского государственного областного университета. Серия: Лингвистика. 2014. № 3. С. 51-56.

\section{REFERENCES}

1. Artem'eva Yu.V., Yavari Yu.V. [Translation of Realia in Cinematography]. In: Vestnik Moskovskogo gosudarstvennogo oblastnogo universiteta. Seriya: Lingvistika [Bulletin of Moscow Region State University. Series: Linguistic], 2018, no. 1, pp. 101-109.

2. Belyaeva I.F., Khukhuni G.T. [Literal translation: the pages of history]. In: Vestnik Moskovskogo gosudarstvennogo oblastnogo universiteta. Seriya: Lingvistika [Bulletin of Moscow Region State University. Series: Linguistic], 2016, no. 1, pp. 108-117.

3. Gavrilenko N.N. Professional'no-orientirovannyi perevod: real'nost' i perspektivy [Profession- 
ally-oriented translation: reality and prospects]. Moscow, Peoples' Friendship University of Russia Publ., 2016. 270 p.

4. Dobryanskaya O.V. Money, banking, accounting [Money, banking, accounting]. St. Petersburg, Saint-Petersburg State University of Economics and Finance Publ., 2010. 100 p.

5. Zhirova I.G. [Academic, publicistic and popular scientific elements in stylistics and semantics of academic paper]. In: Vestnik Moskovskogo gosudarstvennogo oblastnogo universiteta. Seriya: Lingvistika [Bulletin of Moscow Region State University. Series: Linguistic], 2016, no. 2, pp. 41-46.

6. Kardovich I.K. [Cognitive Text Analysis]. In: Vestnik Moskovskogo instituta lingvistiki [Bulletin of the Moscow Institute of Linguistics], 2011, no. 2, pp. 30-35.

7. Kovalenko G.F. Kul'tura rechevogo obshcheniya i perevod (angliiskii yazyk) [Culture of verbal communication and translation (English)]. Khabarovsk, Pacific National University Publ., 2013. 75 p.

8. Korovkina M.E. [Ways of overcoming dissimilarities in the stylistic devices used in the English and Russian languages in the process of translation]. In: Vestnik Moskovskogo gosudarstvennogo lingvisticheskogo universiteta. Seriya: Gumanitarnye nauki [Vestnik of Moscow State Linguistic University. Series: Humanitarian Sciences], 2016, iss. 11 (750), pp. 13-24.

9. Kuznetsova A.V. Pis'mennyi perevod. Angliiskii yazyk [Written translation. English]. Magnitogorsk, Magnitogorsk State University Publ., 2011. 300 p.

10. Kuptsova A.K. Ustnyi perevod (Ekonomika i biznes). Angliiskii yazyk [Interpretation (Economy and business). English]. Moscow, Moscow International Higher Business School MIRBIS (Institute) Publ., 2013. 182 p.

11. Man'kovskaya Z.V. Angliiskii yazyk v situatsiyakh povsednevnogo delovogo obshcheniya [English in everyday business communication]. Moscow, INFRA-M Publ., 2012. 223 p.

12. Migolat'eva I.V. Ustnyi perevod obshchestvenno-politicheskikh tekstov. Angliiskii yazyk [Interpretation of socio-political texts. English]. Moscow, Peoples' Friendship University of Russia Publ., 2014. 47 p.

13. Peresun'ko E.A. Delovoi angliiskii [Business English]. Moscow, Moscow State Forest University Publ., 2012. 100 p.

14. Skazko A.S., Agirbov S.R. [Lexico-semantic peculiarities of scientific and publicist philosophical text in English]. In: Nauka i sovremennost' [Science and Modernity], 2011, no. 13-3, pp. $45-48$.

15. Chernyshova L.A. [International terms as part of professional language world image]. In: Vestnik Moskovskogo gosudarstvennogo oblastnogo universiteta. Seriya: Lingvistika [Bulletin of Moscow Region State University. Series: Linguistic], 2014, no. 3, pp. 51-56.

\section{ИНФОРМАЦИЯ ОБ АВТОРАХ}

Мохова Оксана Леонидовна - кандидат педагогических наук, заведующий кафедрой иностранных языков Московского финансово-промышленного университета «Синергия»; e-mail: mohova_oksana@mail.ru.

Назарова Нина Борисовна - кандидат филологических наук, доцент кафедры иностранных языков Московского финансово-промышленного университета «Синергия»; доцент кафедры лингвистики Российского университета транспорта (МИИТ);

e-mail nina.zavkaf@gmail.com

Серебровская Тамара Борисовна - кандидат педагогических наук, доцент кафедры иностранных языков Московского финансово-промышленного университета «Синергия»; e-mail: tserebrovskaya@yandex.ru 


\section{INFORMATION ABOUT THE AUTHORS}

Oksana L. Mokhova - PhD in Pedagogical sciences, head of the Department of Foreign Languages, Moscow University for Industry and Finance "Synergy";

e-mail: mohova_oksana@mail.ru

Nina B. Nazarova - PhD in Philological Sciences, associate professor at the Department of Foreign Languages, Moscow University for Industry and Finance "Synergy"; associate professor at the Department of Linguistics, Russian University of Transport (MIIT);

e-mail: nina.zavkaf@gmail.com

Tamara B. Serebrovskaya - PhD in Pedagogical Science, associate professor at the Department of Foreign Languages, Moscow University for Industry and Finance "Synergy";

e-mail: tserebrovskaya@yandex.ru

\section{ПРАВИЛЬНАЯ ССЫЛКА НА СТАТЬЮ}

Мохова О.Л., Назарова Н.Б., Серебровская Т.Б. Особенности перевода научно-публицистических текстов // Вестник Московского государственного областного университета. Серия: Лингвистика. 2018. № 6. С. 91-100.

DOI: $10.18384 / 2310-712 \mathrm{X}-2018-6-91-100$

\section{FOR CITATION}

Mokhova O.L., Nazarova N.B., Serebrovskaya T.B. Features of the Translation of Scientific Texts at the Stylistic Level. In: Bulletin of Moscow Region State University. Series: Linguistics, 2018, no. 6, pp. 91-100.

DOI: $10.18384 / 2310-712 \mathrm{X}-2018-6-91-100$ 